\title{
Construction of Local Administrative Licensing Standardization in China: Current Situation, Problem Summary and Path Analysis
}

\author{
Xiao-Wen XU \\ China National Institute of Standardization, No. 4 Zhichun Road, Beijing, China \\ xuxw@cnis.gov.cn
}

Keywords: Administrative licensing, Standardization, Normalization.

\begin{abstract}
Promoting the administrative licensing standardization is an important measure to solve the "difficulty of getting approval" reflected by people, restrain the discretion, reduce the institutional transaction cost and enhance the examination and approval efficiency. So far, some achievements have been made in the promotion of local administrative licensing standardization, but there are still some problems because the administrative licensing standardization is still explored at an initial stage. By arranging and summarizing the practice situations in different places, this paper analyzes the key problems needing to be taken seriously, and brings forward the improved countermeasure and path so as to promote the construction of local administrative licensing standardization.
\end{abstract}

\section{Introduction}

In recent years, our government departments have greatly promoted the reform in such fields as administrative examination and approval and "institute decentralization, combination of decentralization and control and service optimization", and these measures have become an important content of transformation of government functions. Promoting the administrative licensing standardization becomes an important working field at present, which is of great significance to standardize the administrative examination and approval behavior, optimize the administrative examination and approval service and enhance the administrative examination and approval efficiency. In order to intensively solve the prevalent problem of non-standard and non-normalized administrative licensing in various departments under the State Council and various local departments, in July 2016, the Office of Administrative Examination and Approval System Reform under the State Council and the Standardization Administration of China jointly issued Notice on Promoting Administrative Licensing Standardization (Shen Gai Ban Fa [2016] No. 4) and formally released Guidelines for Administrative Licensing Standardization (2016), which marked that the administrative licensing in China preliminarily crossed the threshold of standardization. The Guidelines stipulate the normalized requirements for administrative licensing items, administrative licensing process, administrative licensing service, construction and management of administrative licensing accepting sites as well as the supervision and evaluation, and put forward the specific and operable work guidelines and requirements for promoting administrative licensing standardization throughout the whole country. Since then, the local governments at all levels in China, in combination with the local reality and referring to the standard and Guidelines, have deployed the construction of administrative licensing standardization and made work arrangements and plans.

\section{Review and Arrangement of Current Situation}

Promoting the administrative licensing standardization is an important content of transformation of government functions. Since the documents about promoting the administrative licensing standardization were released, the local governments throughout the country have taken several countermeasures to promote and standardize the administrative licensing behavior and optimize administrative examination and approval service. This part here will arrange and present the current situation of construction of administrative licensing standardization. 


\section{Basic Forms of Local Governments Promoting the Administrative Licensing Standardization}

1.Based on the standardized operating provisions in the Guidelines, documents to guide the construction of administrative licensing standardization are issued. The working programs issued by many provinces and cities mainly focus on management standardization of administrative licensing items, management standardization of administrative licensing process, standardization of administrative licensing service, standardization of construction and management of administrative licensing accepting sites, and supervision, inspection and evaluation. There are few documents issued at the provincial level to promote the administrative licensing standardization. Shanxi Province gives a relatively detailed explanation of the above content. As for the problem of construction scope of administrative licensing standardization, Shanxi Province's working program brings "the government departments (units) entering and stationed in the province government affairs center and carrying out administrative licensing item services into the construction scope of administrative licensing standardization", and makes more definite the scope and limitations of the work.

Besides, the municipal government departments in some regions deploy the work of administrative licensing standardization and make the working programs for or implementation opinions on promoting the administrative licensing standardization. The specific situation is presented as follows: first, although there are some differences in details among the specific requirements for the work of administrative licensing standardization in the documents of different regions, they all raise requirements and make arrangement focusing on item management, process, service, construction and management of accepting sites as well as supervision, inspection and evaluation. Second, in the plan for construction of administrative licensing standardization, the work is divided into different implementation stages according to the nature of work. For example, Nanchong City divides the work five stages - research and preparatory stage, standard-setting stage, implementation organization stage, evaluation and improvement stage, and acceptance inspection stage. Hefei City sets up the following links - making administrative licensing standard template, preparing administrative licensing service standard, promoting the implementation of standards for administrative licensing items, and evaluation and acceptance inspection.

2. The construction of administrative licensing standardization is integrated into "streamline administration and institute decentralization, and combination of decentralization and control". Firstly, continue to deepen the reform of administrative examination and approval system and promote the process of administrative licensing standardization. Further deepen the reform of administrative examination and approval system by comprehensively promoting list management, arranging and normalizing authority and responsibility list, paying attention to linkage of undertaking and coordination, realizing the standardization of examination and approval process, actively exploring the new examination and approval mode and accelerating the establishment of administrative license list. Yunnan Province re-clears and re-defines administrative authority items, studies and explores the classified management, examination and approval of administrative licensing items, prepares and discloses the service guide and operational manual of administrative licensing items, and implements uniform tagging and uniform management of administrative licensing items. Henan Province, by specific "separation of certificate and license" pilot reform, promotes the reform of administrative examination and approval system, arranges the administrative examination and approval items at the pilot site, simplifies the service process, discloses the service procedures, promotes the standardized management and online service, makes clear the examination and approval standards and service time limit and reduce the discretion of examination and approval. Secondly, the construction of administrative licensing standardization is reflected in the reform measures for "institute decentralization, combination of decentralization and control and service optimization" in specific fields. Inner Mongolia Autonomous Region actively promotes the construction of administrative licensing standardization, makes clear the work objectives of "three levels, four sames", (Three levels mean the autonomous region, league city and banner county. Four sames mean the same name, same code, same process and same basis of an administrative examination and approval item.) laying a solid foundation for the practice and play 
of the lists. Allocate special personnel for construction of administrative licensing standardization, provide centralized service and uniform guidance and comprehensively carry out standardization construction. Explore the service model of "online consultation, online application, online examination and approval, network-side push and express delivery", further optimize the examination and approval process and innovate on the examination and approval model. Henan Province raises some requirements for the standardization of tax administrative licensing, such as simplifying the tax administrative licensing application materials, realizing reservation of tax administrative licensing consultation service and improving the mode of service of tax administrative licensing document.

\section{Basic Situation of Local Governments Promoting the Administrative Licensing Standardization}

1.In terms of management standardization of administrative licensing items, arrange and integrate the specific service items, prepare list of administrative licensing items, encode every administrative licensing item for standardization, and form a complete set of clear standardized system of administrative licensing items. For example, based on the principles of statutory authority, giving consideration to both similarities and differences and striving for standardization and uniformity, the Office of Administrative Examination and Approval System Reform of Shandong Provincial Government prepared and issued the Universal Catalog of Administrative Licensing Items of Cities and Counties (Cities and Districts) in Shandong Province, required all the cities and counties should claim items from the Catalog and solve the inconsistency between the items and the name, basis, time limit and charging standard and so on.

2.In terms of administrative licensing process management standardization, the administrative licensing authorities re-arrange and analyze the original contexts of administrative licensing or administrative examination and approval, further optimize the administrative licensing process, stress the key links of administrative licensing, integrate the principles of "being clear and brief, convenient and efficient" into the administrative licensing process standardization management. They arrange and optimize the administrative licensing process, and according to the demands of people and item properties and other standards, divide administrative licensing into different types to re-shape the licensing process. For example, Guangdong Province explores three main types of examination and approval processes. For simple items, it carries out "service on arriving" or "on-the-spot service"; for relatively professional items, it explores to merge examination and decision link with personnel and realize the "integration of examination and decision"; for cross-level items involving special procedures, it explores the cross-level and cross-department flat and parallel service.

3.In terms of administrative licensing service standardization, the administrative licensing enforcement authorities, in combination with the reality of administrative licensing items, should not only conduct standardized management over administrative licensing items and the process, but also should further normalize and standardize the relevant supporting systems and rules, prepare clear and definite service guides, open smooth and efficient consultation channels and build online administrative licensing service platform if conditions permits. Some regions try to solve the problem of operational norms of the examination and approval staffs in the service process, make clear the essential conditions, procedures and discretion and other standards of examination and approval, organize the preparation of operational manual and service guides, and solve the problems of different materials, different procedures and different results when different staffs handle the same item.

4.In terms of standardization of construction and management of administrative licensing accepting sites, the construction and management of administrative licensing accepting sites become an important prerequisite and guarantee of effectively promoting the administrative licensing standardization. This requires full consideration and measurement of quantity, applications and quantity of service organizations of administrative licensing items, reasonable setting of accepting sites, establishment of corresponding management mechanism, and uniform 
arrangement and management of administrative licensing enforcement authorities entering the service center. So far, the achievements in this aspect have included the following: the governments build administrative affair hall and promote the entry of administrative licensing items, integrate the service windows set up by departments into a comprehensive service window, comprehensively coordinate the authority of different windows in the examination and approval of administrative licensing items; the staff of government affair center, in strict accordance with the administrative licensing standards, uniformly accept the items at the front desk comprehensive service window; then, the department examination and approval staffs carry out the classified examination and approval behind the scenes; then, the front desk comprehensive service window issues the licenses uniformly.

\section{Analysis and Summary of Key Problems}

Based on the summary of and analysis on current practices of administrative licensing standardization in different provinces and cities, it is found that there are a lot in common, and a good expected result has been obtained in the overall work of administrative licensing standardization. But in some specific details, it is easy to find some key problems needing urgent solutions.

\section{Problems in Items and Process Management of Administrative Licensing Standardization Construction}

1.Problem of establishing and improving the basic list of administrative licensing items and uniformly encoding and managing them. Firstly, the names of administrative examination and approval items are not standard enough and the "granularity" is too high. So far, the names of administrative examination and approval items vary from region to region, and even from place to place in the same region. Some names cannot reflect the connotation of examination and approval items, which greatly confuses the people and enterprises. At the same time, the administrative examination and approval items don't realize "smallest granule" and cannot correspond to the requirements "one examination and approval for one item, one process for one item"; and there are many gray zones in the examination and approval process. Secondly, the basic list and encoding of administrative licensing items are stereotyped and cannot adapt to the requirements for adjustment of administrative licensing items and reform of administrative licensing reform. In the implementation process of administrative examination and approval, the administrative licensing items will meet the problems of adding, reduction and change, but the stereotyped list and encoding management of administrative licensing items cannot correspond to the normative and instructional Guide Catalog, which will cause much inconvenience to the licensing departments and item applicants.

2. Problem of optimizing the administrative licensing process. When optimizing the licensing process, the administrative licensing enforcement authorities at all levels should follow the principle of making it convenient for the applicants, make clear the processing conditions and methods, simplify the acceptance documents, cut down the processing time limit and maximally make it convenient for the enterprises and people. However, the fact is that there are some problems in the administrative licensing process: firstly, "rigid uniformity" processing model exists in the optimization of administrative licensing process. The differences of different administrative licensing items in the examination and approval process are ignored, but all the approval processes are rigidly divided into several co-existing links - acceptance, examination, approval, accreditation and service; there is no recognition and flexible treatment of particularity of administrative licensing items, as a result of which there are some unnecessary links in the administrative licensing process and the administrative efficiency is low. At the same time, the administrative licensing process is optimized in isolation. There are many problems when it coordinates with the preparation of service guide, preparation of detailed rules of examination and adjustment of application materials; and there are repetitions in the verification and approval at different stages. Secondly, the optimization and re-creation of administrative licensing process is faced with the problems of too 
many application materials, unreasonable examination and approval conditions and tedious processing links arising from lagging legislation. The provisions of the existing legal basis for administrative licensing process become the causes for some departments to refuse to simplify and optimize the administrative licensing items, which increases the difficulty to optimize and re-create the administrative licensing process.

\section{Problem of Imperfect Administrative Licensing Standardization System and Administrative Examination and Approval System}

1. A complete and coordinating system for administrative licensing standardization construction has not been formed. In the process of promoting the administrative licensing standardization construction, some helpful explorations are made centering on the administrative licensing service specifications, site construction and management specifications. But, in the aspect of process specifications and specifications for supervision, inspection and evaluation, the local government departments just conducted exploration and pilot work in the relevant aspects and haven't make standards because it is hard to accurately grasp the reform requirements and reform direction. In this case, there will be no standard and normative management and business guidance for the management of administrative licensing items entering the government affair hall and online service platform. Besides, it is difficult to coordinate when the administrative licensing standardization is promoted at the municipal and county levels. Firstly, the difficulty is from laws and regulations. There are conflicts or difference between some requirements in Administrative Licensing Law and the realistic administrative licensing situations. Secondly, there are no specific provisions for the enforcement of some administrative licensing in the laws and regulations. In face of the top-down reform of administrative examination and approval, the cities and counties usually enforce the requirements in the normative documents that have not been cleared by the superior industry sector, and it is hard to effectively clear and standardize the examination and approval conditions and materials.

2. The support of the existing examination and approval system for the Superior industry sector construction is insufficient. The examination and approval window involves the online examination and approval system of government affair service center at the same level, business system of the same department, the provincial administrative power network operation system as well as the superior industry management department's special network system, but the data of these systems cannot effectively dock with each other; the data and information resources cannot be shared; multiple type-ins are usually needed when different departments or systems collect relevant information. All of these greatly reduce the processing efficiency of administrative licensing items and to a large extent, hinder the progress of administrative licensing standardization construction. In addition, the population information, legal person information and credit information at different levels cannot be shared, and the service systems such as "one window acceptance" and "one network processing" lack the support of the required data resources and coordinating and sharing mechanisms of the system; and the validity of e-signature, e-certificate and e-document have not been settled legally. These problems of the existing examination and approval systems impose many limitations on innovating on and optimizing the examination and approval system links in the process of administrative licensing standardization construction.

\section{Problems in Application Materials of Administrative Licensing Items and Enforcement Mechanism of Administrative Licensing Standardization}

1.The application materials and forms are tedious and repetitive, which is a barrier to simplify the examination and approval model and realization of paperless examination and approval. There are a lot of irrelevant, unnecessary and tedious materials in the administrative licensing application. For one thing, more time is spent on the examination and verification of examination and approval materials for administrative licensing items, which extends the time limit for processing the administrative licensing. For another, in order to guarantee the smooth examination and approval process, the applicants need to prepare perfect and detailed application materials in advance, and this undoubtedly increases stress and difficulty in the early stage of processing the licensing items. 
The tedious and repetitive application materials and forms cannot satisfy the requirements of proper simplification and optimization, and are completely incompliant with the trend of administrative licensing standard construction and reform of administrative examination and approval system. At present, the construction of big data of service items, online application of licensing items and one-window-for-several-functions service model require simplification of application materials and forms and even paperless examination and approval. But as far as the actual situation of application materials is concerned, the simplification and integration of administrative licensing application materials become an important problem in the administrative licensing standardization construction.

2.The enforcement mechanism of administrative licensing standardization is imperfect and it is hard to implement the licensing standards. After the standards for administrative licensing items are made and issued, how to enforce the standards becomes a key problem. Because there is no carrier to enforce the standards and no system to promote the enforcement, many regions lay aside and neglect the standards after making them; and in the process of processing administrative licensing items, few people and examination and approval staffs use them, making the work of making standards and promoting standardization meaninglessly. The enforcement of multi-department and multi-item joint licensing standard prepared centering on different "theme services" meets a lot of difficulties and problems. For one thing, many laws, regulations and rules are drafted by departments and carried out mainly by departments, and there are some conflicts or contradictions among different laws, regulations and rules in some industry or fields. As a result, it is hard to reach coordination and unity when joint licensing standards are made. For another, because the departments generally carry out administrative licensing according to the laws, regulations and rules of their own departments, they are generally not enthusiastic for leading to carry out relevant joint licensing activities, and some departments even worry that they have to assume some extra responsibilities if they take the lead. All these problems become hinders for the local governments to promote administrative licensing standardization.

\section{Exploration of and Reflection on Countermeasure Path}

\section{Promote Administrative Licensing Standardization by Standardizing Examination and Approval Items, Process and System}

1. Arrange and adjust administrative licensing items, comprehensively enhance the examination and approval efficiency. Comprehensively re-arrange and re-confirm the items, comprehensively promote the management system of various lists, adjust and optimize the department responsibilities, really place the power in the system framework and operate it normatively. At the same time, make standards according to the authorities and responsibilities of the region, arrange and standardize the list of authorities and responsibilities and regularly adjust it dynamically to constantly enhance the scientific and standardized level of administrative licensing work; continue to increase the administrative power cancellation and decentralization, and except the items that require provincial examination and approval such as safety, environment protection and important resources layout and control, "stop examination and approval" at the provincial level for the enterprise investment projects encouraged and permitted by the country. On the basis of comprehensively arranging the functions and powers of the department directly under the province, further define the administrative power items that should be decentralized. If the administrative power items which in principle should be transferred to the city or county level must be reserved, they should be re-cleared and re-defined; the basis for this should be listed and a list of them should be made.

2.On the basis of arranging and adjusting administrative licensing items, make a catalog of administrative licensing items to standardize the examination and approval behavior. Preparing a catalog of administrative licensing items creates institutional convenience for realizing the standard examination and approval services and efficient examination and approval; implementing management of intermediary organ of administrative examination and approval and list of intermediary services standardizes the service process, charging standard, service time limit and 
service guide of prepositive intermediary organ of administrative examination and approval, and disclose it to the public. The administrative licensing items at all levels in the whole province should be encoded and managed uniformly; the service guide and operational manual of administrative licensing items should be prepared and disclosed; classified management, examination and approval of administrative licensing items should be actively explored and studied, and the standardization process of administrative examination and approval should be comprehensively accelerated. Further clear the administrative licensing items; list all the administrative licensing items that are being enforced in the catalog; cancel the administrative licensing items unlisted in the catalog; don't enforce administrative licensing beyond the catalog; comprehensively standardize the administrative licensing behavior and accept the social supervision.

3.Optimize the administrative examination and approval process. On the basis of consolidating the relatively centralized reform achievements of administrative licensing power, select the highly motivated region to carry out pilot work, preliminarily realize the online parallel examination and approval by clearly standardizing the prepositive elements of examination and approval and intermediary service items and simplifying the examination and approval process, and further shorten the processing time. For example, in the aspect of special tax facilitation work, promote some specific "short, flat and fast" measures to make the tax handling links simpler, process better, materials fewer and time limit shorter.

\section{Innovating on Administrative Examination and Approval Model}

By comprehensively promoting streamline administration and institute decentralization, force all the levels and departments to reduce, transfer and govern powers, quickly form a "one-for-all" mechanism covering such fields as administrative licensing, administrative punishment, administrative collection, administrative adjudication and government affair. Greatly promote the model of "approval without meeting", accelerate the reform measures of "online processing, centralized approval, joint examination, regional evaluation, acting system, no meeting", comprehensively promote the processing model of "online consultation, online application, online examination and approval, network-side push and express delivery"; at the same time, complete the docking between "one-paper examination and approval network" and "multiple regulations in one" information management platform where the examination and approval department can refer to related information of "one-paper blueprint" to assist the examination and approval. Try to operate "one-window acceptance" and realize integrated examination and approval services of "one-window acceptance, internal circulation, joint examination and approval, completion within a time limit". Focus on promoting "one-window acceptance" at the government affair center, based on the idea and goal of "handling all affairs at the government by people and enterprises at most once", start from the fields and items with the closest relationship with the enterprises and people's production and life, try to integrate the service windows set up by the departments into a comprehensive window, carry out front desk comprehensive acceptance, classified examination and approval behind the scenes, and uniform document issues at the window so as to avoid people's travel between different departments.

\section{Greatly Promote "Internet +", and Maximally Serving People}

Actively make use of "internet + government service", promote the "one-paper examination and approval network" to the village and sharing of multi-system docking data, and realize the four-level interactive online examination and approval. Meanwhile, try to promote the "approval without meeting" on the internet in the whole process. Promote "approval without meeting", make the people "hardly travel" from "travel little". Promote the comprehensive implementation of approval without meeting" on the internet in the whole process at three levels - provincial level, city and county level, and town (district) level. With the goal of people and enterprises handling affairs at the government departments and enterprises and institutions "without going there" or "at most going there once", further improve the standardization construction of online service hall. 
By strengthening the support of public technological environment, such as online real name authentication, express service and payment service, improve the "internet + government service" platform and build a multi-level linking, standard and transparent, resource-sharing and service-coordinating online government service system. For example, accelerate the construction of government affair data sharing platform and realize the data interconnection between the self-built examination and approval service systems of the departments at all levels and the examination and approval processing system of the government service center at all levels so as to further solve the problems of information barrier and secondary type-in, realize information sharing, achieve the purpose of "one-paper network for examination and approval", and make the local online processing of administrative licensing items basically realized.

\section{Construct a Perfect Administrative License Standard System}

The "five-in-one" administrative licensing standardization system contains the specifications and standards for administrative licensing items, licensing process, licensing service, licensing accepting sties, supervision, inspection and evaluation; and the requirements for administrative licensing items, process and links are also involved. Centering on the requirements of "one standard for one item, one specification for one process", cancel the illegal examination and approval items, service items and application materials, simplify and standardize the evaluation and examination links, prepare the operating instructions for each administrative licensing item, and build an all-round administrative licensing standard system.

Try to build an administrative licensing standard system covering "all items, all processes and all links". "Enhance the gold content of decentralization, strengthen the effectiveness of control, promote the facilitation of services, constantly deepen the reform of "institute decentralization, combination of decentralization and control and service optimization", and focus on stimulating the vitality of the main market players. Centering on accelerating the transformation of government functions, constantly deepen the reform of streamline administration and institute decentralization, compare the key points with catalog of items cancelled and adjusted by the State Council and the provincial government, further enhance the gold content of streamline administration and institute decentralization, strictly control the newly added examination and approval items and the prepositive conditions, comprehensively standardize the administrative examination and approval behavior, make and issue the guiding opinions on promoting the management of administrative licensing standardization. Meanwhile, comprehensively promote the facilitation of administrative examination and approval service, fully apply the thinking of "internet + government services", promote the management of administrative licensing standardization, and build an administrative licensing standard system covering "all items, all processes and all links". By applying principles, methods and technologies of standardization, in combination with the current administrative examination and approval, complete the preparation and audit of administrative licensing service standards and specifications and standards for administrative licensing service, plan and prepare the encoding rules, service guide specification and detailed rules of item examination of administrative licensing items, promote the administrative licensing standardization and normalization.

\section{Acknowledgements}

This article in this phase is part of a state-funded key research program, namely, Research on General Technical Standards for Administrative Services and Licenses (No.572017Z-5592-01) \& dean fund program of China National Institute of Standardization, namely, Study on the Standardization of Administrative Approval of the National Administrative Approval Standardization Working Group - 2018 (No.572018Y-5939-2018). 


\section{References}

[1] JZBF (2016) No. 168, "Notice of the General Office of the People's Government of Shanxi Province on Printing and Distributing the Work Plan for Accelerating the Standardization of Administrative Licensing of Provincial Government Departments” [Z](In Chinese).

[2] BZ (2017) No. 73, “Notice of the People's Government of Anhui Province on Announcing Catalogue of Power and Responsibilities of Provincial Governments in Anhui Province (2017 Edition)” [Z](In Chinese).

[3] YZB (2017) No. 84, "Notice of the General Office of the People's Government of Henan Province on Printing and Distributing Henan's Five Special Work Plans for the Reform of the 'Simplified Administration, Decentralization, Integration and Optimization of Services' in 2017” [Z](In Chinese).

[4] NZFD (2017) No. 26, “Notice of the People’s Government of Inner Mongolia Autonomous Region on Printing and Distributing Autonomous Regions's Advancement of the Work Plan of Simplified Administration, Decentralization, Integration and Optimization of Services in 2017" [Z](In Chinese).

[5] Zhejiang Provincial Development and Reform Commission Department of Social Reform. Our Province has Actively Promoted the Standardization of Administrative Examination and Approval and Boosted the "Run at most once" Reform. http://www.zjdpc.gov.cn/art/2017/3/1/art_109_1723164.html.(In Chinese) 